\title{
Is there a correlation between depressive symptoms and motor skills in post-stroke patients?
}

\author{
Existe correlação entre sintomas depressivos e habilidades motoras em pacientes \\ pós-AVC?
}

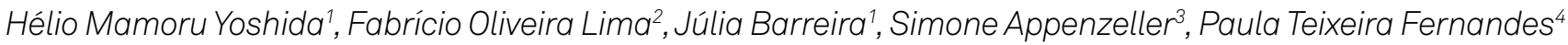

\begin{abstract}
Deficits in motor skills and depressive symptoms are common effects observed after stroke, so it is necessary to understand how these variables interact with each other. Therefore, the aim of this study was to investigate the relationship between these two variables in postischemic stroke patients. We evaluated 135 patients with a mean age of 60 years $( \pm 15)$. The Fugl-Meyer assessment of motor function was used to assess motor skills in the upper limbs, lower limbs, balance, and sensitivity and the Beck Depression Inventory was applied to evaluate depressive symptoms. To assess the relationship between both components, Spearman's correlation was performed. Depressive symptoms were negatively correlated with all variables of motor skills. This study suggests that higher motor skills in post-stroke patients may be associated with fewer depressive symptoms. Thus, a better understanding of how post-stroke symptoms are interrelated may improve patient treatment and care, contributing to a better quality of life.
\end{abstract}

Keywords: Stroke; motor skills; depression.

\section{RESUMO}

Déficits na habilidade motora e presença de sintomas depressivos são comuns em pacientes pós-AVC. Assim, é necessário compreender como estas variáveis interagem entre si. O objetivo deste trabalho foi verificar esta relação em pacientes pós-AVC isquêmico. Participaram 135 sujeitos, com idade média de 60 anos ( \pm 15 ). Foi utilizado o protocolo de desempenho motor Fugl Meyer para verificar a habilidade motora dos membros superiores, inferiores, equilíbrio e sensibilidade e o Inventário de Depressão de Beck para verificar os sintomas depressivos. Foi realizada a análise de Spearman para verificar a relação entre os dois componentes. Os sintomas depressivos se correlacionaram negativamente com todas as variáveis da habilidade motora. Assim, a maior habilidade motora implicou em menores sintomas depressivos. Portanto, compreender como as sequelas pós-AVC se relacionam auxilia no melhor tratamento e atendimento ao paciente, contribuindo para melhorar sua qualidade de vida.

Palavras-chave: Acidente vascular cerebral; destreza motora; depressão.

The World Health Organization defines stroke as "a rapid development of clinical signs of focal or generalized cerebral function disturbance with symptoms of at least 24 hours and possibly leading to death without any apparent cause, apart from the vascular" (p. 108) $)^{1}$. Currently, stroke is regarded as the second leading cause of death worldwide ${ }^{2}$. The literature describes a similar rate in Brazil ${ }^{3}$.
The most common effect of stroke is motor impairment. More than half of the stroke survivors suffer from permanent physical disabilities ${ }^{4}$.

The motor impairment includes effects in the upper limbs, trunk, gait and balance ${ }^{5}$. Furthermore, understanding motor impairment is important, as it has a direct impact on the patient's quality of life ${ }^{6}$. Depressive symptoms are also a

\footnotetext{
${ }^{1}$ Universidade Estadual de Campinas, Faculdade de Educação Física, GEPEN - Grupo de Estudos em Psicologia do Esporte e Neurociências, Campinas SP, Brasil; ${ }^{2}$ Hospital Geral de Fortaleza, Fortaleza, CE, Brasil;

${ }^{3}$ Universidade Estadual de Campinas, Faculdade de Ciências Médicas, Campinas SP, Brasil.

«Universidade Estadual de Campinas, Faculdade de Educação Física, GEPEN - Grupo de Estudos em Psicologia do Esporte e Neurociências, Departamento de Ciência do Esporte, Campinas, SP, Brasil.

Paula Teixeira Fernandes (iD) https://orcid.org/0000-0002-0492-1670

Correspondence: Paula Teixeira Fernandes; Faculdade de Educação Física da Unicamp, Departamento de Ciências do Esporte; Av. Érico Veríssimo, 701 -Cidade Universitária Zeferino Vaz, Barão Geraldo; 13083-851 Campinas SP, Brasil; E-mail: paula@fef.unicamp.br

Conflict of interest: There is no conflict of interest to declare.

Received 20 November 2017; Received in final form 04 October 2018; Accepted 23 November 2018.
} 
common impairment after stroke ${ }^{7}$, affecting between $10 \%$ to $78 \%$ of post-stroke patients ${ }^{8}$.

Data presented by Kotila et al. ${ }^{9}$ showed that more than half of the post-stroke patients suffered from depression, and despite symptoms persisting for a year, many depressed patients did not seek out appropriate treatment. It is critical, therefore, that post-stroke depression should be diagnosed as quickly as possible, to avoid greater losses in other spheres of the patient's life, such as negative consequences to social and family relationships ${ }^{10}$.

A study by Carod-Artal et al. ${ }^{11}$, drawing on data from 260 patients, showed that depression and physical disabilities were consistent contributors to the worsening of quality of life in post-stroke patients. However, studies have been inconclusive, due to different results presented in the literature ${ }^{12}$.

Physical activity could improve post-stroke quality of life by reducing the chances of hypertension, diabetes mellitus and body weight, which are some of the greatest risk factors for stroke ${ }^{13}$. Furthermore, exercise has been shown to improve motor function ${ }^{14}$ and potentially reduce depressive symptoms ${ }^{15}$. Health professionals could benefit from a better understanding of how the interaction between physical activity, depressive symptoms, and post-stroke quality of life works, before they plan a physical exercise program, as there is still a gap in the understanding of the relationship between motor skills and depressive symptoms. Furthermore, motor ability and depressive symptoms may have a strong correlation, and pharmacological treatment of depression could improve motor rehabilitation ${ }^{16}$. In this context, the present study aimed to identify the relationship between motor skills and depressive symptoms in post-ischemic stroke patients.

\section{METHODS}

\section{Participants}

We evaluated 135 adult patients of both sexes, diagnosed with single, unilateral, ischemic stroke of the anterior circulation vessels, confirmed by magnetic resonance imaging. All participants signed the free and informed consent form approved by the Research Ethics Committee of Unicamp (approval number CAAE: 0321.0.146.000-11). Patients with a history of more than a single stroke event, hemorrhagic stroke, ischemic stroke with hemorrhagic transformation, and posterior circulation ischemic stroke were excluded. All participants were treated at the Neurovascular Program, UNICAMP's Clinics Hospital, in Campinas, Brazil.

\section{Instruments}

Three questionnaires were applied to the participants:

1) Structured identification questionnaire: information about age, sex, laterality, physical activity, associated diseases and lifestyle habits (smoking, drinking, and use of other drugs). Regarding habits, the questions covered two life periods, exploring whether a particular habit was currently present in the participant's life, including after the stroke, or if it was a habit only in the past (prior to ischemic stroke).

2) Fugl-Meyer Motor Scale (FMMS): specific to the evaluation of motor skills in stroke patients, internationally validated with reliability in Brazil ${ }^{17}$. The FMMS protocol evaluates the patient's motor impairment in three functions: motor impairment of the upper limbs, the lower limbs, and balance. These dimensions are organized on an ordinal scale from 0 to 2, where 0 corresponds to no performance and 2 indicates proper performance. Thus, the higher the score, the higher the patient's motor skills ${ }^{18}$.

3) Beck's Depression Inventory (BDI): assessment of depressive symptoms through 21 questions about everyday situations related to depression. Responses vary in intensity from 0 to 3 , where 0 indicates a low-intensity of symptoms and 3 indicates a high-intensity of symptoms. The score classification is: a score of less than 10 indicates few or no depressive symptoms; between 10 and 18, minimum to moderate depressive symptoms; between 19 and 29 moderate to severe depressive symptoms; between 30 and 63 , severe depressive symptoms ${ }^{19}$. The BDI is validated for Brazilian Portuguese ${ }^{20,21}$.

\section{Procedure}

Participants attended the Neuroimaging Laboratory at UNICAMP at a previously-scheduled date and time, in order to collect research data for this study. After receiving a briefing of the study and signing the informed consent form, patients answered the questionnaire, FMMS, and BDI in the presence of responsible researchers. Each patient's assessment lasted approximately 50 minutes. Conditions were similar for all subjects.

\section{Statistics}

Continuous variables were expressed as median and interquartile range (non-normal distribution), or mean and standard deviation (normal distribution). Categorical variables were expressed as percentages and absolute values. In order to verify the association of depressive symptoms and motor skills, Spearman's correlation coefficient was used. All statistical results with a $\mathrm{p}$ value $<0.05$ were considered to be statistically significant. All statistical analyses were performed using Minitab' 16 software (Minitab Inc. State College, Pa).

\section{RESULTS}

Altogether, 135 subjects were evaluated ( 80 men; mean age, $60 \pm 15$ years; time post-stroke $16.66 \pm 29.66$ months). Regarding laterality, 93.99\% $(\mathrm{n}=126)$ were right-handed. Of the total, $26.67 \%(n=36)$ had a history of participating in 
Table 1. General characteristics of 135 post-stroke patients.

\begin{tabular}{|c|c|}
\hline Variables & Values \\
\hline \multicolumn{2}{|l|}{ Characteristics } \\
\hline Age (years, mean $\pm S D$ ) & $60( \pm 15)$ \\
\hline Sex (male, \%) & $80(59.26 \%)$ \\
\hline History of physical activity (frequency, \%) & $36(26.67 \%)$ \\
\hline Right hemisphere stroke & $64(47 \%)$ \\
\hline Right laterality (frequency, \%) & $126(93.33 \%)$ \\
\hline Time after ischemic stroke (months, mean \pm SD) & $16.66( \pm 29.66)$ \\
\hline \multicolumn{2}{|l|}{ Lifestyle habits } \\
\hline Smoking - currently (frequency, \%) & $25(18.66 \%)$ \\
\hline Smoking - past (frequency, \%) & $79(62.70 \%)$ \\
\hline Drinking - currently (frequency, \%) & $39(29.55 \%)$ \\
\hline Drinking - past (frequency, \%) & $77(68.75 \%)$ \\
\hline \multicolumn{2}{|l|}{ Associated diseases } \\
\hline High blood pressure (frequency, \%) & $91(67.41 \%)$ \\
\hline Diabetes (frequency, \%) & $32(23.70 \%)$ \\
\hline Dyslipidemia (frequency, \%) & $30(22.22 \%)$ \\
\hline Heart disease (frequency, \%) & $20(14.81 \%)$ \\
\hline History of depression (frequency, \%) & $4(2.9 \%)$ \\
\hline
\end{tabular}

Table 2. Motor skills of 135 post-stroke patients on the Fugl-Meyer Motor Scale.

\begin{tabular}{lccccccccc}
$\begin{array}{l}\text { Motor skills on the Fugl-Meyer } \\
\text { motor scale }\end{array}$ & $\mathrm{N}$ & Mean & $\mathrm{SD} \pm$ & Minimum & Median & $\begin{array}{c}\text { Maximum } \\
\text { IR1 (25\%) }\end{array}$ & $\begin{array}{l}\text { IR3 (75\%) } \\
\text { \% of maximum } \\
\text { score }\end{array}$ \\
\hline Upper limbs & 66 & 56.3 & 16.36 & 0 & 64 & 66 & 57 & 66 & $84 \%$ \\
Lower limbs & 34 & 29.02 & 8.35 & 0 & 33 & 34 & 27.25 & 34 & $85 \%$ \\
Balance & 14 & 10.97 & 3.72 & 0 & 12 & 14 & 10 & 14 & $71 \%$ \\
Sensitivity & 24 & 21.89 & 4.84 & 0 & 24 & 24 & 20.25 & 24 & $91 \%$ \\
Upper limbs + lower limbs & 100 & 85.33 & 23.87 & 0 & 96 & 100 & 85 & 99.75 & $85 \%$ \\
Total & 138 & 118.19 & 30.45 & 0 & 131 & 138 & 116.5 & 136 & $85 \%$ \\
\hline
\end{tabular}

IR: interquartile range.

physical activities. History of smoking and alcohol use was $62.70 \%(n=79)$ and $68.75 \%(n=77)$, respectively. High blood pressure was the most common associated disease $(n=91$, $67.41 \%)$. Of the total patients, $2.9 \%(n=4)$ had depression. All patients' demographic and clinical characteristics are shown in Table 1.

Regarding motor ability, Table 2 shows the values for each domain, which include upper limbs, lower limbs, balance, sensitivity, the sum of upper and lower limbs, and total motor skill score. Furthermore, the last column shows the percentage achieved for each domain, where the higher the percentage, the lower the impairment. Balance had the lowest percentage $(71 \%)$.

Depressive symptoms (Table 3 ) are categorized by intensity. Most patients presented with minimal symptoms ( $\mathrm{n}=$ $77,57.03 \%$ ), followed by mild symptoms ( $\mathrm{n}=47,34.81 \%$ ), moderate symptoms $(\mathrm{n}=9,6.66 \%)$, and severe symptoms $(\mathrm{n}=2,1.48 \%)$.
Table 3. Depressive symptoms of 135 post-stroke patients.

\begin{tabular}{lc} 
Depressive symptoms & $\begin{array}{c}\text { Frequency } \\
(\%)\end{array}$ \\
\hline Minimal symptoms (score lower than 10) & $77(57.03 \%)$ \\
\hline Mild symptoms (score between 10 and 18) & $47(34.81 \%)$ \\
\hline Moderate symptoms (score between 19 and 29$)$ & $9(6.66 \%)$ \\
\hline Severe symptoms (score between 30 and 63$)$ & $2(1.48 \%)$ \\
\hline Total (mean \pm SD) & $9.93( \pm 7.14)$ \\
\hline
\end{tabular}

Depressive symptoms and distribution of symptom intensity in the sample according to the Beck Depression Inventory.

Regarding correlations, through our analysis we found a weak negative correlation between depressive symptoms and all categories of motor skills. In other words, patients with higher motor skills exhibited a reduced intensity of depressive symptoms. Table 4 shows the values of Spearman's correlation coefficient in accordance with the 
Table 4. Correlation coefficients between the Fugl-Meyer, Beck Depression Inventory, age, and post-stroke time in days.

\begin{tabular}{|c|c|c|c|c|c|c|c|c|c|c|c|c|c|c|}
\hline \multirow{3}{*}{ Variable } & \multirow{2}{*}{\multicolumn{2}{|c|}{ BDI }} & \multicolumn{12}{|c|}{ Fugl-Meyer } \\
\hline & & & \multicolumn{2}{|c|}{ Upper limbs } & \multicolumn{2}{|c|}{ Lower limbs } & \multicolumn{2}{|c|}{ Balance } & \multicolumn{2}{|c|}{ Sensitivity } & \multicolumn{2}{|c|}{$\begin{array}{l}\text { Upper limbs + } \\
\text { lower limbs }\end{array}$} & \multicolumn{2}{|c|}{ Total } \\
\hline & $r$ & $p$-value & $r$ & p-value & $r$ & $p$-value & $r$ & $p$-value & $r$ & $\mathrm{p}$-value & $r$ & $\mathrm{p}$-value & $r$ & $p$-value \\
\hline $\mathrm{BDI}$ & & & -0.35 & $<0.01$ & -0.32 & 0.01 & -0.23 & $<0.01$ & -0.36 & $<0.01$ & -0.37 & $<0.01$ & -0.41 & $<0.01$ \\
\hline Age & -0.23 & 0.01 & -0.12 & 0.18 & -0.11 & 0.2 & -0.38 & $<0.01$ & 0.15 & 0.08 & -0.12 & 0.15 & -0.16 & 0.07 \\
\hline Time & 0.04 & 0.62 & -0.03 & 0.75 & 0.02 & 0.78 & -0.12 & 0.15 & -0.03 & 0.73 & -0.01 & 0.91 & -0.02 & 0.82 \\
\hline
\end{tabular}

BDI: Beck's Depression Inventory; r: analysis Spearman's rho; $p<0.05$; Time: time after stroke.

correlation shown for each component of motor skills and depressive symptoms.

Moreover, further correlations between motor ability, depressive symptoms, age and time after stroke were made. Time after stroke and age had very weak correlations with both motor skills and depressive symptoms. Balance had a weak correlation.

\section{DISCUSSION}

This study aimed to evaluate the relationship between motor skills and depressive symptoms in post-ischemic stroke patients. This study found a negative correlation between those variables. Results showed that patients with better motor skills exhibited fewer depressive symptoms, suggesting a possible interference of psychological aspects in motor performance, indicating a complex interaction between these aspects.

Regardingmotor skills, astudybyWood-Dauphineeetal. ${ }^{22}$ showed an FMMS score of 24.21 ( \pm 23.70) for upper limbs and $15.65( \pm 11.20)$ for lower limbs in 167 patients with acute ischemic stroke. Our patients showed a higher average of $56.30( \pm 16.36)$ and $29.02( \pm 8.35)$ for upper and lower limbs, respectively.

On a 0-100 scale (upper and lower limbs), our participants had a mean score of $85.33( \pm 23.87)$. Oliveira et al. ${ }^{23}$ observed a mean score of $53.35( \pm 28.44)$ in 20 patients after applying the same motor scale. However, there were no data regarding the type of stroke analyzed in their study, which may have contributed to the difference between the reported results. Similar to our results, a study by Hsieh et al. ${ }^{24}$ showed an average of $52.8( \pm 34.5)$ for 169 patients, using the same instrument. Those differences could be justified by the periods of post-stroke testing: our study averaged 11.66 months after stroke, whereas Hsieh's study averaged 14 days after stroke.

Balance was the most-affected aspect. Our study showed a score of 10.97 ( \pm 3.72 ), representing $71 \%$ of the maximum (14 points). Oliveira et al. ${ }^{23}$ found similar results, with balance rates of $10.8( \pm 1.24)$ in 20 patients of both sexes. The study by Hsieh et al. ${ }^{24}$ showed an average of $6.4( \pm 4.5) 14$ days after the stroke event, using the same instrument. Furthermore, our results showed a weak correlation between age and balance, indicating a worse balance in older patients post-stroke. We can hypothesize that balance may be associated with other post-stroke outcomes, as only balance had percentages below $80 \%$ of the maximum.

Regarding psychological aspects, Terroni et $a .^{25}$ showed that post-stroke patients had a prevalence of depression between $23 \%$ and $60 \%$. Aben et al. ${ }^{8}$ showed a variation between $10 \%$ and $78 \%$. Fernandes ${ }^{10}$ explained that such variation was influenced by location and date of where the assessment was held; type of care; study characteristics; criteria under evaluation; and instruments. According to our results, $57.03 \%$ of the patients had minimal symptoms, $34.81 \%$ had mild symptoms, $6.66 \%$ had moderate symptoms, and $1.48 \%$ had severe symptoms, which is in accordance with previous studies.

We highlight that depression may have negative effects during the recovery period, impairing rehabilitation ${ }^{26}$. Preventive measures against depressive symptoms, in association with motor rehabilitation, may improve cognitive aspects $^{27}$ and positively impact quality of life ${ }^{11}$.

It is important to note that the literature is not conclusive regarding the relationship between depressive symptoms and motor skills. A study by Weaver et al. ${ }^{12}$, with 118 patients, found no relationship between motor skills of the upper limbs and depressive symptoms, contrasting with the results presented in this study, where an inverse relationship was measured between depressive symptoms and all aspects of general motor skills.

Our results were consistent in identifying a correlation measured between the variables analyzed, even for a group in which $91.84 \%$ of the patients had minimal to mild depressive symptoms. It is worth mentioning that our study showed a negative correlation between depressive symptoms and all components of motor skills.

These results corroborate Herrmann's et al. ${ }^{28}$, who found a correlation between major depressive symptoms and lower motor skills performance, also showing an inverse relationship between depressive symptoms and motor skills. In our study, motor skills were directly related to functional performance, as the protocol we used assessed the patient's ability to perform movements. In addition to our study, other researchers ${ }^{929}$ have also obtained a negative association between the studied variables. 
Despite a weak correlation, our work reaffirmed findings from major sources in the literature, associating both aspects post-stroke. Thus, our findings contribute to existing knowledge about stroke disease, which continues to be a considerable life event, affecting millions of people worldwide. Additionally, this study showed that depressive symptoms were related to motor skills in their different components (upper and lower limbs, and balance) in a single group of patients.

In this way, the results demonstrated the importance of analyzing all components of motor skills, as they are related to depressive symptoms differently, to enable the development of specific programs geared to the individualized needs of patients.

Regarding limitations and future directions, there are a few considerations to make. First, we did not measure the presence of small vessel diseases, or white-matter hyperintensities signals in MRI scans, both of which could contribute to confounding the results. Second, in conducting this study, we considered a high heterogeneity in motor and mood aspects. Our sample comprised diverse patients with a considerable range of depressive symptoms: 77 (57\%) with minimal symptoms and 11 (8\%) with severe symptoms; and, regarding motor skills, they had a wide range of impairment levels (mean of 118.19 and standard deviation of \pm 30.45 ). Further studies should consider separate analyses of different levels of impairment, and increase the number of participants. Third, it is known that patients with pre-stroke depression are more likely to develop post-stroke depres$\operatorname{sion}^{30}$. This predictor deserves special attention, as do the possible effects of medication, for data analysis in future studies. Fourth, we suggest following up on patients in order to better understand at least two aspects: variation in motor and depressive symptoms over time, and variation in the correlation between motor skills and depressive symptoms. Fifth, future studies should consider different aspects that could influence both motor skills and mood alterations, such as particular cognitive aspects and neurologic state, so that supplementary correlations can be made. Sixth, supplementary analyses could be carried out, to check if those correlations remain in acute and chronic phases, in post-stroke patients.

Finally, we would emphasize that one of the most effective intervention strategies is improving the development of all professionals involved in the health and care systems, in order to prevent harm and support the patients' rehabilitation. This is necessary to more clearly identify physical and psychological factors that can contribute to a better prognosis for those patients.

In conclusion, this study identified a weak negative relationship between motor skills and depressive symptoms in postischemic stroke patients. Patients with more intense depressive symptoms exhibit greater dysfunctions in motor skills.

Identifying this relationship could be important. Our results highlighted the relevance of providing health professionals with information to contribute more effectively to treatments and, consequently, improve quality of life for stroke patients.

Through our analysis we conclude that depressive symptoms, as well as age, may impact motor skills. Consequently, we emphasize that a physical exercise program in poststroke patients may improve their quality of life and reduce mood disorders.

\section{Acknowledgments}

Coordenação de Aperfeiçoamento de Pessoal de Nível Superior (Coordination for the Improvement of Higher Education Personnel), process no: 01-P-03504/2014.

\section{References}

1. WHO MONICA Project Principal Investigators. The World Health Organization MONICA Project (monitoring trends and determinants in cardiovascular disease): a major international collaboration. J Clin Epidemiol. 1988;41(2):105-14 https://doi.org/10.1016/0895-4356(88)90084-4

2. World Health Organization - WHO. WHO methods and data sources for global causes of death 2000-2011. Geneva: World Health Organization; 2013.

3. Ministério da Saúde (BR). Health Brazil, 2009: an analysis of the health situation and the national and international agenda of health priorities.Brasilia, DF: Ministério da Saúde; 2010.

4. Pantano P, Totaro P, Raz E. Cerebrovascular diseases. Neurol Sci. 2008 Oct;29(S3 Suppl 3):314-8. https://doi.org/10.1007/s10072-008-1006-2

5. Likhi M, Jidesh VV, Kanagaraj R, George JK. Does trunk, arm, or leg control correlate best with overall function in stroke subjects? Top Stroke Rehabil. 2013 Jan-Feb;20(1):62-7. https://doi.org/10.1310/tsr2001-62
6. Mayo NE, Wood-Dauphinee S, Côté R, Durcan L, Carlton

J.Activity, participation, and quality of life 6 months poststroke. Arch Phys Med Rehabil. 2002 Aug;83(8):1035-42. https://doi.org/10.1053/apmr.2002.33984

7. Sinanović O. Neuropsychology of acute stroke. Psychiatr Danub. 2010 Jun;22(2):278-81.

8. Aben I, Verhey F, Honig A, Lodder J, Lousberg R, Maes M. Research into the specificity of depression after stroke: a review on an unresolved issue. Prog Neuropsychopharmacol Biol Psychiatry. 2001 May;25(4):671-89. https://doi.org/10.1016/S0278-5846(01)00158-0

9. Kotila M, Numminen $\mathrm{H}$, Waltimo O, Kaste M. Depression after stroke: results of the FINNSTROKE Study. Stroke. 1998 Feb;29(2):368-72. https://doi.org/10.1161/01.STR.29.2.368

10. Fernandes PT. Psicologia e AVC: qual a relação? In: Li ML, Fernandes P, Avelar W, Martins S, editors. AVC: da pesquisa à aplicação clínica. São Paulo: Plêiade; 2013. P. 210-65. 
11. Carod-Artal J, Egido JA, González JL, Varela de Seijas E. Quality of life among stroke survivors evaluated 1 year after stroke: experience of a stroke unit. Stroke. 2000 Dec;31(12):2995-3000. https://doi.org/10.1161/01.STR.31.12.2995

12. Weaver LL, Page SJ, Sheffler L, Chae J. Minimal depression: how does it relate to upper-extremity impairment and function in stroke? Am J Occup Ther. 2013 Sep-Oct;67(5):550-5. https://doi.org/10.5014/ajot.2013.008391

13. Tumasz MT, Trócoli T, Oliveira MF, Campos RR, Botelho RV. Do Physically Active Patients Have Better Functional Outcome after Stroke? A Systematic Review. J Stroke Cerebrovasc Dis. 2016 Mar;25(3):527-32. https://doi.org/10.1016/j.jstrokecerebrovasdis.2015.10.034

14. Pin-Barre C, Laurin J. Physical exercise as a diagnostic, rehabilitation, and preventive tool: influence on neuroplasticity and motor recovery after stroke. Neural Plast. 2015;2015:ID608581. https://doi.org/10.1155/2015/608581.

15. Smith PS, Thompson M. Treadmill training post stroke: are there any secondary benefits? A pilot study. Clin Rehabil. 2008 Oct-Nov;22(10-11):997-1002. https://doi.org/10.1177/0269215508088988

16. Babul MR, Hassanuzzaman, Ahammed Z, Kibria A, Faruk G, Azam A et al. Fluoxetine for Motor recovery after acute ischemic stroke: a randomized placebo-controlled trial. Am J Psychiatry Neurosci. 2017;5(3):31-6. https://doi.org/10.11648/j.ajpn.20170503.11

17. Maki T, Quagliato E, Cacho EWA, et al. Estudo de confiabilidade da aplicação da escala de FuglMeyer no Brasil. Rev Bras Fisioter. 2006;10(2):177-83. https://doi.org/10.1590/S1413-35552006000200007

18. Fugl-Meyer AR, Jääskö L, Leyman I, Olsson S, Steglind S. The post-stroke hemiplegic patient. 1. a method for evaluation of physical performance. Scand J Rehabil Med. 1975;7(1):13-31.

19. Beck AT, Steer RA, Carbin MG. Psychometric properties of the Beck Depression Inventory: twenty-five years of evaluation. Clin Psychol Rev. 1988;8(1):77-100. https://doi.org/10.1016/0272-7358(88)90050-5

20. Gorestein C, Andrade L. Inventário de depressão de Beck : propriedades psicométricas da versão em português Índice. Rev Psiq Clin. 1998;25(5):245-50.
21. Cunha JA. Manual da versão em português das Escalas Beck. Sâo Paulo Casa do Psicólogo; 2001.

22. Wood-Dauphinee SL, Williams JI, Shapiro SH. Examining outcome measures in a clinical study of stroke. Stroke. 1990 May;21(5):731-9. https://doi.org/10.1161/01.STR.21.5.731

23. Oliveira R, Cacho EW, Borges G. Post-stroke motor and functional evaluations: a clinical correlation using Fugl-Meyer assessment scale, Berg balance scale and Barthel index. Arq Neuropsiquiatr. 2006 Sep;64(3b 3B):731-5. https://doi.org/10.1590/S0004-282X2006000500006

24. Hsieh CL, Sheu CF, Hsueh IP, Wang CH. Trunk control as an early predictor of comprehensive activities of daily living function in stroke patients. Stroke. 2002 Nov;33(11):2626-30. https://doi.org/10.1161/01.STR.0000033930.05931.93

25. Terroni LM, Leite CC, Tinone G, Fráguas R Jr. [Poststroke depression: risk factors and antidepressant treatment]. Rev Assoc Med Bras (1992). 2003 Oct-Dec;49(4):450-9. Portuguese. https://doi.org/10.1590/S0104-42302003000400040

26. Gainotti G, Antonucci G, Marra C, Paolucci S. Relation between depression after stroke, antidepressant therapy, and functional recovery. J Neurol Neurosurg Psychiatry. 2001 Aug;71(2):258-61. https://doi.org/10.1136/jnnp.71.2.258

27. Kimura M, Robinson RG, Kosier JT. Treatment of cognitive impairment after poststroke depression: a double-blind treatment trial. Stroke. 2000 Jul;31(7):1482-6. https://doi.org/10.1161/01.STR.31.7.1482

28. Herrmann N, Black SE, Lawrence J, Szekely C, Szalai JP. The Sunnybrook Stroke Study: a prospective study of depressive symptoms and functional outcome. Stroke. 1998 Mar;29(3):618-24. https://doi.org/10.1161/01.STR.29.3.618

29. Singh A, Black SE, Herrmann N, Leibovitch FS, Ebert PL, Lawrence J, et al. Functional and neuroanatomic correlations in poststroke depression: the Sunnybrook Stroke Study. Stroke. 2000 Mar;31(3):637-44. https://doi.org/10.1161/01.STR.31.3.637

30. Lewin A, Jöbges M, Werheid K. The influence of self-efficacy, pre-stroke depression and perceived social support on self-reported depressive symptoms during stroke rehabilitation. Neuropsychol Rehabil. 2013;23(4):546-62. https://doi.org/10.1080/09602011.2013.794742 